\title{
Níveis de Energia Digestível para Suínos Machos Castrados dos 30 aos 60 kg Mantidos em Ambiente de Alta Temperatura 1
}

\section{Sandra Lúcia da Silva Tavares ${ }^{2}$, Juarez Lopes Donzele ${ }^{3}$, Rita Flávia Miranda de Oliveira ${ }^{3}$, Aloísio Soares Ferreira ${ }^{3}$, Dalton de Oliveira Fontes ${ }^{2}$}

\begin{abstract}
RESUMO - Com o objetivo de avaliar os efeitos de níveis de energia digestível (ED) sobre o desempenho e a taxa de composição da carcaça, foram usados 50 suínos machos castrados, dos 30 aos $60 \mathrm{~kg}$ de $\mathrm{PV}$, mantidos em ambiente de alta temperatura $\left(32,00 \pm 0,88^{\circ} \mathrm{C}\right)$. Foi usado delineamento em blocos ao acaso, com cinco tratamentos (3100, 3250, 3400, 3550 e 3700 kcal de ED/kg de ração), cinco repetições e dois animais por unidade experimental. O nível de ED da ração influenciou quadraticamente o ganho de peso diário e os consumos de ração, energia e proteína dos animais. A conversão alimentar melhorou linearmente em função dos níveis crescentes de ED da ração. O nível de ED da ração não influenciou a taxa de deposição de proteína, mas a deposição de gordura aumentou linearmente. Os melhores resultados de ganho de peso foram obtidos com o nível estimado de $3486 \mathrm{kcal}$ de ED, enquanto o nível de 3700 kcal de ED proporcionou os melhores resultados de conversão alimentar.
\end{abstract}

Palavras-chave: crescimento, estresse por calor, exigência, desempenho, composição de carcaça

\section{Digestible Energy Levels for Barrows from 30 to $60 \mathrm{~kg}$ Maintained in a High Environment Temperature}

\begin{abstract}
With the objective to evaluate the effects of digestible energy (DE) on the performance and carcass composition rate, 50 barrows, from 30 to $60 \mathrm{~kg} \mathrm{PV}$, maintained in a high temperature environment $\left(32.00 \pm .88^{\circ} \mathrm{C}\right)$ were used. A completely randomized block design with five treatments $(3100,3250,3400,3550$, and $3700 \mathrm{kcal}$ of DE/kg of diet), five replicates and two animals per experimental unit was used. The dietary DE level influenced,in a quadratic way, the daily weight gain and the feed, energy and protein intakes of the animals. Feed:gain ratio linearly improved with increasing dietary DE levels. The DE level did not influence the protein deposition rate, but the fat deposition increased linearly. The best results of weight gain were obtained with the estimate level of $3486 \mathrm{kcal}$ DE, while the level of $3700 \mathrm{kcal}$ DE provided the best results of feed:gain ratio.
\end{abstract}

Key Words: growth, heat stress, requirement, performance, carcass composition

\section{Introdução}

A reação do suíno ao estresse de calor envolve respostas fisiológicas e comportamentais que influenciam o desempenho produtivo animal, como redução no consumo voluntário de alimentos, perda de peso e mobillização da gordura corporal.

Temperatura ambiente acima da zona termoneutra eleva a temperatura corporal de modo que o animal reduz o consumo de alimentos para reduzir a produção de calor associada com a ingestão, digestão, absorção e metabolismo dos alimentos, prevenindo aumento excessivo da temperatura corporal (FORBES, 1995).

Como forma de amenizar os efeitos do estresse de calor, tem-se enfatizado a necessidade de melhor adequação das dietas às condições de ambiente. A suplementação extra de energia por meio do uso de óleos e gorduras tem resultado em redução do calor produzido no metabolismo pelos suínos, devido ao seu baixo incremento calórico. Além disso, por apresentarem alta densidade energética, óleos e gorduras, ajudam a compensar a redução do consumo de energia (FIALHO, 1994).

Estudos conduzidos por STAHLY e CROMWELL (1979) evidenciaram efeito positivo da suplementação de gordura sobre a taxa de crescimento e eficiência de uso da energia por suínos em crescimento e terminação submetidos à alta temperatura $\left(35^{\circ} \mathrm{C}\right)$.

As altas temperaturas ambiente também influenciam a utilização de energia pelos suínos, alterando a composição de sua carcaça. OLIVEIRA et al. (1997) observaram aumento linear na taxa de deposição de proteína e variação quadrática na taxa de deposição

\footnotetext{
${ }^{1}$ Parte da tese de Doutorado - Projeto financiado pela FAPEMIG.

${ }^{2}$ Aluno do curso de Doutorado, DZO - UFV.

${ }^{3}$ Professor do DZO - UFV.
} 
de gordura na carcaça de leitões dos 15 aos $30 \mathrm{~kg}$ mantidos em ambiente de alta temperatura $\left(32^{\circ} \mathrm{C}\right)$, em razão do aumento do nível de energia da ração.

O presente trabalho teve por objetivo avaliar rações isoprotéicas com diferentes níveis de energia digestível para suínos machos castrados dos 30 aos $60 \mathrm{~kg}$ de peso, mantidos em ambiente de alta temperatura $\left(32^{\circ} \mathrm{C}\right)$.

\section{Material e Métodos}

O experimento foi conduzido no Setor de Suinocultura do Departamento de Zootecnia do Centro de Ciências Agrárias da Universidade Federal de Viçosa, em Viçosa, MG.

A temperatura média interna da sala foi mantida por meio de um conjunto de seis aquecedores, tipo campânulas de resistência, ligados a um termostato regulado para a temperatura de $32^{\circ} \mathrm{C}$. Os termostatos e os equipamentos de medição ambiental (termômetros de bulbo seco e bulbo úmido, de máxima e mínima e de globo negro), foram instalados em uma gaiola vazia no centro da sala a uma altura correspondente à do animal. As leituras dos instrumentos foram realizadas às 8 e $16 \mathrm{~h}$.

As condições térmicas da sala durante o período experimental foram $32,00 \pm 0,88^{\circ} \mathrm{C}$ de temperatura média do ar; 32,29 $\pm 0,58$ de temperatura máxima média do ar; 31,30 $\pm 0,61$ de temperatura mínima média do ar; $76,73 \pm 5,39 \%$ de umidade relativa; $31,83 \pm 2,00^{\circ} \mathrm{C}$ de temperatura de globo negro; e 82,85 $\pm 2,14$ de Índice de Temperatura de Globo e Umidade.

Grupos de dois animais foram alojados em gaiolas metálicas, suspensas, com piso e laterais ripados, dotadas de comedouros semi-automáticos e bebedouro tipo chupeta, localizadas em sala de alvenaria com piso de concreto e forro de madeira rebaixada, dotada de janelões de vidro tipo basculante.

Utilizaram-se 50 machos castrados, mestiços, com peso inicial médio de $30,67 \pm 1,36 \mathrm{~kg}$, distribuídos em delineamento experimental de blocos ao acaso com cinco tratamentos $(3100,3250,3400,3550$ e $3700 \mathrm{kcal}$ de energia digestível (ED)/ $\mathrm{kg}$ de dieta), cinco repetições e dois animais por unidade experimental. $\mathrm{Na}$ formação dos blocos foram adotados como critério o peso inicial e o parentesco dos animais.

As dietas experimentais (Tabela 1) foram fornecidas à vontade e formuladas de forma a atender as necessidades de vitaminas e minerais dos animais, com o nível de proteína bruta $10 \%$ acima do recomendado por ROSTAGNO et al. (1992), e os níveis de energia digestível obtidos por meio de alterações das
Tabela 1 - Composição das rações experimentais (\%)

Table 1 - Composition of the experimental diets

\begin{tabular}{|c|c|c|c|c|c|}
\hline \multirow{2}{*}{$\begin{array}{l}\text { Ingrediente }(\%) \\
\text { Ingredient }\end{array}$} & \multicolumn{5}{|c|}{$\begin{array}{c}\text { Nível de energia digestível (kcal/kg) } \\
\text { Digestible energy level }\end{array}$} \\
\hline & 3100 & 3250 & 3400 & 3550 & 3700 \\
\hline Milho & 54,19 & 54,19 & 54,19 & 54,19 & 54,19 \\
\hline \multicolumn{6}{|l|}{ Corn } \\
\hline Farelo de soja & 22,26 & 22,26 & 22,26 & 22,26 & 22,226 \\
\hline $\begin{array}{l}\text { Soybean meal } \\
\text { Farelo de trigo } \\
\text { Wheat bran }\end{array}$ & 10,00 & 10,00 & 10,00 & 10,00 & 10,00 \\
\hline $\begin{array}{l}\text { Fosfato bicálcico } \\
\text { Dicalcium phosphate }\end{array}$ & \multicolumn{5}{|c|}{ Dicalcium phosphate } \\
\hline Calcário & 0,90 & 0,90 & 0,90 & 0,90 & 0,90 \\
\hline $\begin{array}{l}\text { Limestone } \\
\text { Mistura mineral }^{1} \\
\text { Mineral mix }\end{array}$ & 0,10 & 0,10 & 0,10 & 0,10 & 0,10 \\
\hline $\begin{array}{l}\text { Mistura vitamínica }{ }^{2} \\
\text { Vitamin mix }\end{array}$ & 0,10 & 0,10 & 0,10 & 0,10 & 0,10 \\
\hline Sal & 0,34 & 0,34 & 0,34 & 0,34 & 0,34 \\
\hline \multicolumn{6}{|l|}{ Salt } \\
\hline Óleo de soja & 0,50 & 2,50 & 4,50 & 7,00 & 9,70 \\
\hline \multicolumn{6}{|l|}{ Soybean oil } \\
\hline $\begin{array}{l}\text { Corn starch } \\
\text { Areia lavada }\end{array}$ & \multicolumn{5}{|c|}{ Corn starch } \\
\hline Washed sand & 6,09 & 4,33 & 2,58 & 1,40 & 0,44 \\
\hline \multicolumn{6}{|c|}{ Composição calculada ${ }^{3}$} \\
\hline $\mathrm{ED}(D E) \quad(\mathrm{kcal} / \mathrm{kg})$ & 3100 & 3250 & 3400 & 3550 & 3700 \\
\hline Proteína bruta $(\%)$ & 16,50 & 16,50 & 16,50 & 16,50 & 16,50 \\
\hline $\begin{array}{l}\text { Crude protein } \\
\text { Lisina }(\%) \\
\text { Lysine }\end{array}$ & 0,84 & 0,84 & 0,84 & 0,84 & 0,84 \\
\hline $\mathrm{Ca}(\%)$ & 0,68 & 0,68 & 0,68 & 0,68 & 0,68 \\
\hline $\mathrm{P}(\%)$ & 0,54 & 0,54 & 0,54 & 0,54 & 0,54 \\
\hline \multicolumn{6}{|c|}{ 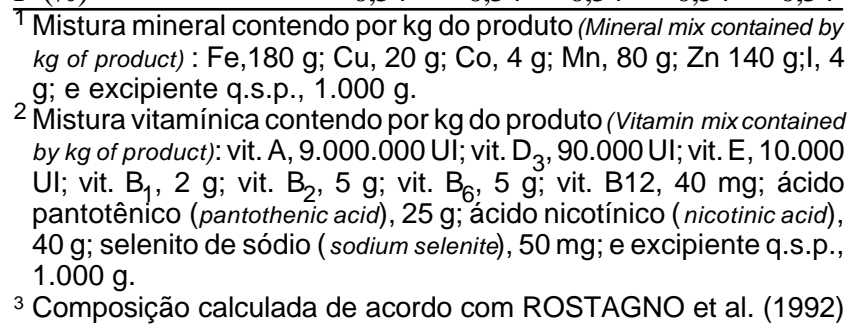 } \\
\hline Calculated composition & & ROSTAG & & & \\
\hline
\end{tabular}

concentrações de óleo, amido e areia lavada.

As sobras de ração foram pesadas semanalmente. Os animais foram pesados ao final do experimento, quando atingiram, em média, 59,89 $\pm 3,23 \mathrm{~kg}$, para determinação do ganho de peso, do consumo de ração e conversão alimentar.

Um grupo adicional de cinco machos castrados, com peso médio de $30,20 \pm 0,92 \mathrm{~kg}$, foi abatido para determinação da composição da carcaça dos animais no início do experimento. No final do experimento, 
após jejum de 24 horas, os animais de cada tratamento foram abatidos, por sangramento, depilados e eviscerados. Após pesagem, as carcaças foram divididas em corte longitudinal e a metade direita das carcaças foram trituradas, por 15 minutos, em "cutter" comercial de $30 \mathrm{HP}$ e 1775 revoluções por minuto. Após a homogeneização, retiraram-se amostras que foram estocadas em freezer.

As amostras de carcaça pré-secas, em estufa de ventilação forçada, $\mathrm{a} \pm 60^{\circ} \mathrm{C}$ por 96 horas, foram prédesengorduradas pelo método a quente no extrator tipo "soxhlet", por cinco horas, para posterior moagem e análises de proteína e gordura das amostras conforme recomendações de SILVA (1990).

As taxas de deposição de gordura e proteína nas carcaças foram calculadas com base nas composições das carcaças dos animais no início e no final do experimento.

As análises estatísticas das variáveis de desempenho e taxas de deposição de gordura e proteína nas carcaças foram realizadas por intermédio do programa ANOVAG, contido no pacote computacional SAEG (Sistema para Análises Estatísticas e Genéticas), segundo o modelo estatístico:

$$
Y_{i j}=\mu+E_{i}+B_{j}+e_{i j}
$$

em que

$\mathrm{Y}_{\mathrm{ij}}=$ ganho peso, consumo de ração, conversão alimentar e taxas de deposição de proteína e gordura referentes ao nível de energia i no bloco j;

$\mu=$ média geral da característica;

$\mathrm{E}_{\mathrm{i}}=$ efeito do nível de energia $\mathrm{i}$;

$\mathrm{B}_{\mathrm{j}}=$ efeito do bloco $\mathrm{j}$; e

$\mathrm{e}_{\mathrm{ij}}=$ erro aleatório associado a cada observação.

\section{Resultados e Discussão}

Os resultados de desempenho, consumos de energia digestível e proteína bruta e taxas de deposição de proteína e gordura na carcaça são apresentados na Tabela 2. Foi observado efeito quadrático $(\mathrm{P}<0,05)$ dos níveis de energia (ED) sobre o ganho de peso diário (GPD), que aumentou até o nível de $3486 \mathrm{kcal}$ de ED, conforme a equação $\hat{Y}=-5197,3+3,41689 X-0,00049046 X^{2}$ (Figura 1). A melhora verificada no ganho de peso até o nível estimado pode ser explicada, entre outros fatores, pelo aumento no consumo de ração e, conseqüentemente, nos de energia e proteína. Por outro lado, o resultado obtido no tratamento em que se utilizou o nível de 3100 kcal de ED revelou que o consumo de ED de $5900 \mathrm{kcal}$ foi insuficiente para garantir bom desempenho em ganho de peso dos animais.

Estes resultados diferem dos obtidos por STAHLY e CROMWELL (1979) e OLIVEIRA et al. (1997), que não observaram variação no ganho de peso, em razão do aumento do nível de energia da ração, dos

Tabela 2 - Desempenho, consumos de energia digestível e proteína e taxas de deposição de proteína gordura de suínos machos castrados dos 30 aos $60 \mathrm{~kg}$ de peso consumindo rações com níveis crescentes de energia digestível sob alta temperatura

Table 2 - Performance, intake of digestible energy and protein, and rate deposition of protein and fat in barrows from 30 to $60 \mathrm{~kg}$ fed diets with increasing levels of energy in a high temperature

\begin{tabular}{|c|c|c|c|c|c|c|}
\hline \multirow[t]{2}{*}{ Item } & \multicolumn{5}{|c|}{$\begin{array}{l}\text { Nível de energia digestível }(\mathrm{kcal} / \mathrm{kg}) \\
\text { Digestible energy level }\end{array}$} & \multirow[t]{2}{*}{$\begin{array}{l}\mathrm{CV} \\
(\%) \\
\end{array}$} \\
\hline & 3100 & 3250 & 3400 & 3550 & 3700 & \\
\hline $\begin{array}{l}\text { Ganho de peso }(\mathrm{g} / \mathrm{dia})^{1} \\
\text { Weight gain }\end{array}$ & 680 & 722 & 775 & 724 & 741 & 4,1 \\
\hline $\begin{array}{l}\text { Consumo de ração }(\mathrm{g} / \mathrm{dia})^{1} \\
\text { Feed intake }\end{array}$ & 1902 & 1936 & 1993 & 1836 & 1751 & 4,5 \\
\hline $\begin{array}{l}\text { Conversão alimentar }{ }^{4} \\
\text { Feed:gain ratio }\end{array}$ & 2,80 & 2,68 & 2,57 & 2,53 & 2,37 & 4,1 \\
\hline $\begin{array}{l}\text { Consumo de } \mathrm{ED}(\mathrm{kcal} / \mathrm{dia})^{2} \\
\text { DE intake }\end{array}$ & 5898 & 6293 & 6777 & 6518 & 6480 & 4,6 \\
\hline $\begin{array}{l}\text { Consumo de proteína }(\mathrm{g} / \mathrm{dia})^{1} \\
\text { Protein intake } \\
\text { Taxas de deposição na carcaça } \\
\text { Deposition rate in the carcass }\end{array}$ & 314 & 319 & 329 & 303 & 289 & 4,5 \\
\hline $\begin{array}{l}\text { Proteína (g/dia) } \\
\text { Protein }\end{array}$ & 91,41 & 91,65 & 94,62 & 92,30 & 88,78 & 10,5 \\
\hline $\begin{array}{l}\text { Gordura } \quad(\mathrm{g} / \mathrm{dia})^{3} \\
\text { Fat }\end{array}$ & 160,87 & 164,91 & 206,28 & 191,46 & 207,78 & 24,2 \\
\hline
\end{tabular}




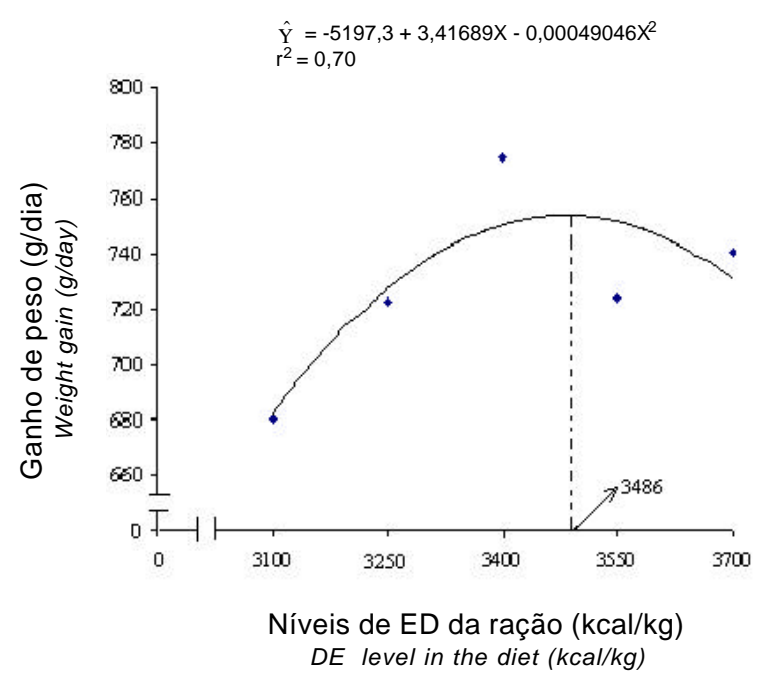

Figura 1 - Regressão do ganho de peso diário de suínos machos castrados dos 30 aos $60 \mathrm{~kg} \mathrm{PV}$, em condições de alta temperatura ambiente, em relação ao nível de ED da ração.

Figure 1 - Regression of the daily weight gain on the dietary $D E$ level for barrows from 30 to $60 \mathrm{~kg} \mathrm{LW}$ in a high environment temperature.

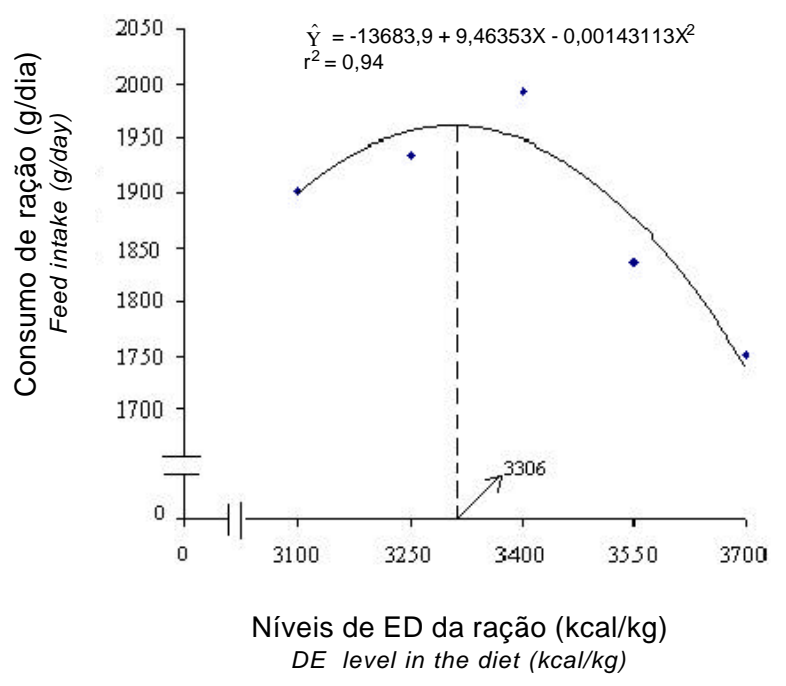

Figura 2 - Regressão do consumo de ração diário de suínos machos castrados dos 30 aos $60 \mathrm{~kg}$ PV, em condições de alta temperatura ambiente, em relação ao nível de ED da ração.

Figure 2 - Regression of the daily feed intake on the dietary $D E$ level for barrows from 30 to $60 \mathrm{~kg}$ in a high environment temperature. suínos em terminação, dos 15 aos $30 \mathrm{~kg}$, respectivamente, submetidos ao estresse de calor.

O consumo de ração diário $(\mathrm{CR})$ variou de forma quadrática $(\mathrm{P}<0,05)$ conforme a equação $\hat{\mathrm{Y}}=-13683,9$ $+9,46353 X-0,00143113 X^{2}$ (Figura 2), aumentando até o nível de $3306 \mathrm{kcal}$ de ED. Por outro lado, STAHLY e CROMWELL (1979) e SCHENCK et al. (1992) não verificaram efeito da suplementação de gordura na ração sobre o consumo de ração de suínos em crescimento e terminação e leitões desmamados, respectivamente, expostos ao calor.

A variação observada no consumo de ração permitiu inferir que, nos níveis mais altos de ED, 3550 e $3700 \mathrm{kcal}$, os animais pareceram ajustar seus consumos em função da energia da ração.

Os níveis de ED da ração influenciaram $(\mathrm{P}<0,01)$ a conversão alimentar (CA) dos animais, que melhorou de forma linear, conforme a equação $\hat{Y}=4,87340$ - 0,0067138X (Figura 3). O possível aumento gradativo da energia líquida das rações, em razão da redução do seu incremento calórico proporcionado pela inclusão de níveis crescentes de óleo de soja, pode justificar a melhoria ocorrida na CA dos animais.

De forma similar, SEERLEY et al. (1978), STAHLY e CROMWELL (1979) e COFFEY et al. (1982) constataram melhoria na conversão alimentar de suínos expostos ao calor, em razão do aumento da densidade energética da ração obtida pela adição de gordura. De acordo com FIALHO (1994), a suplementação de gordura nas rações de suínos em épocas de calor, por proporcionar redução na quantidade de calor produzido pelos suínos, resulta em melhor desempenho dos animais.

Da mesma forma que o consumo de ração, o consumo de energia diário (CED) variou de forma quadrática $(\mathrm{P}<0,01)$ aumentando até o nível de $3491 \mathrm{kcal}$ de ED, conforme a equação $\hat{Y}=-55552,0+35,6464 X-$ $0,00510579 X^{2}$ (Figura 4). Estes resultados contrastam com os obtidos por OLIVEIRA et al. (1997), que observaram variação quadrática no CED de leitões dos 15 aos $30 \mathrm{~kg}$ mantidos em ambiente de alta temperatura $\left(32^{\circ} \mathrm{C}\right)$, porém com redução até o nível estimado de $3391 \mathrm{kcal}$ de ED.

O consumo de proteína diário (CPD) foi quadraticamente influenciado $(\mathrm{P}<0,05)$ pelo nível de ED da ração aumentando até o nível de $3306 \mathrm{kcal}$, segundo a equação $\hat{Y}=-2257,84+1,56148 X-0,000236136 X^{2}$ (Figura 5). Em razão de as rações serem isoprotéicas, a variação verificada no CPD está diretamente relacionada com os resultados de consumo de ração.

Com relação à taxa de deposição de proteína (TDP) na carcaça dos animais, não se verificou variação em razão dos tratamentos, apesar da redução no consumo de proteína. No entanto, observou- 


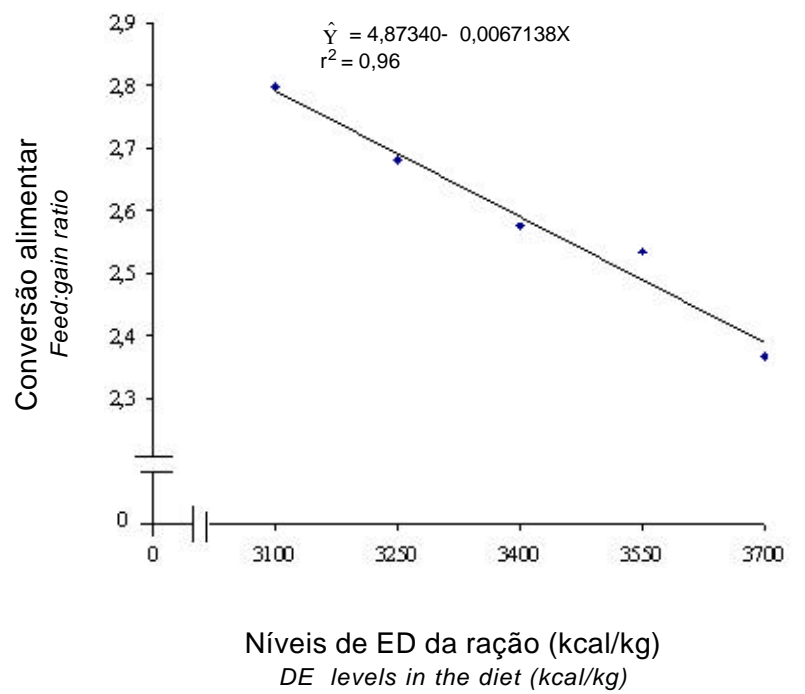

Figura 3 - Regressão da conversão alimentar de suínos machos castrados dos 30 aos $60 \mathrm{~kg} \mathrm{PV}$, em condições de alta temperatura ambiente, em relação ao nível de ED da ração.

Figure 3 - Regression of the feed:gain ratio on the dietary DE level for barrows from 30 to $60 \mathrm{~kg} L W$ in a high environment temperature.

se redução não-significativa de $6,59 \%$ na TDP dos animais que receberam a ração de $3700 \mathrm{kcal}$ de ED relacionada à redução significativa de $13,84 \%$ no $\mathrm{CPD}$, sugerindo que o consumo de proteína foi o fator limitante na deposição de proteína.

Resultados semelhantes foram constatados por STAHLY e CROMWELL (1979), que não observaram variação na composição em proteína da carcaça de suínos dos 24 aos $93 \mathrm{~kg}$, expostos a altas temperaturas ambiente. No entanto, OLIVEIRA et al. (1997) observaram aumento linear na taxa de deposição de proteína da carcaça de suínos machos castrados dos 15 aos $30 \mathrm{~kg}$ de peso, expostos ao calor, em razão dos níveis de ED da ração.

Com base nos resultados de consumo de proteína e de TDP na carcaça, deduziu-se que a não variação na TDP relacionou-se com o fato de que, possivelmente, os animais atingiram sua capacidade de retenção de nitrogênio no consumo de proteína de $303 \mathrm{~g} /$ dia.

Embora o consumo de ED tenha aumentado somente até o nível estimado de $3491 \mathrm{kcal}$ de ED, a taxa de deposição de gordura (TDG) na carcaça aumentou $(\mathrm{P}<0,05)$ de forma linear entre os níveis

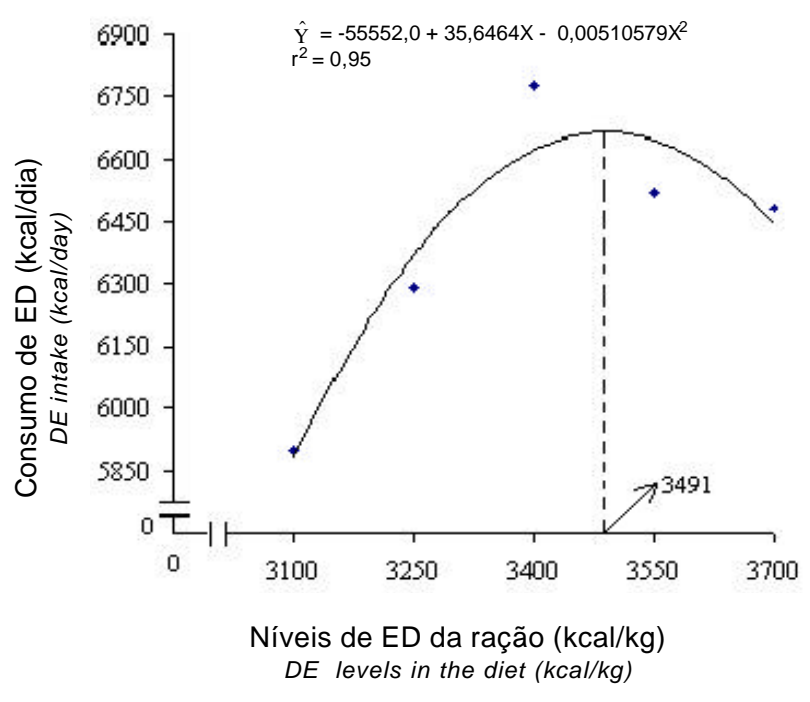

Figura 4 - Regressão do consumo de ED diário de suínos machos castrados dos 30 aos $60 \mathrm{~kg} \mathrm{PV}$, em condições de alta temperatura ambiente, em relação ao nível de ED da ração.

Figure 4 - Regression of the DE intake on the dietary DE level for barrows from 30 to $60 \mathrm{~kg} \mathrm{LW}$ in a high environment temperature.

de 3100 a $3700 \mathrm{kcal}$ de ED, conforme a equação $\hat{\mathrm{Y}}=-86,5922+0,0802501 \mathrm{X}$ (Figura 6). Apesar da variação linear da TDG, verificou-se a ocorrência de um platô a partir do nível de 3400 kcal de ED, porém o modelo de regressão Linear Response Plateau LRP não foi o que melhor se ajustou aos dados.

$\mathrm{O}$ fato de os animais que receberam os tratamentos com 3550 e $3700 \mathrm{kcal}$ terem apresentado valores absolutos de TDG semelhantes aos daqueles que receberam o nível de $3400 \mathrm{kcal}$, apesar de seus menores consumos de ED, pode ser explicado pelo possível aumento da energia líquida das rações, devido aos maiores níveis de inclusão de óleo. Segundo SPEER (1991), a adição de gordura a ração aumenta a eficiência de uso da energia e a deposição de gordura na carcaça.

Estudando o efeito da temperatura ambiente sobre a retenção de energia de suínos em crescimento, SCHOENHERR et al. (1987) verificaram que a adição de gordura à ração aumentou a retenção de gordura pelos animais submetidos a temperatura de $35^{\circ} \mathrm{C}$ e concluíram que a energia derivada da gordura é mais eficientemente utilizada para retenção da energia em proteína e gordura que a de uma ração à base de milho e soja. 


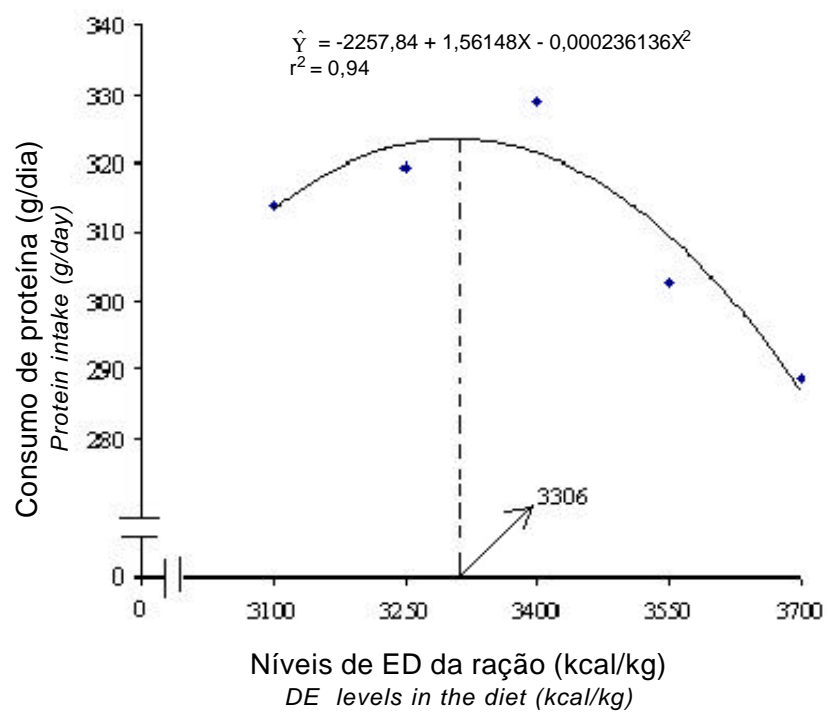

Figura 5 - Regressão do consumo de proteína diário de suínos machos castrados dos 30 aos $60 \mathrm{~kg}$ PV em condições de alta temperatura ambiente em relação ao nível de ED da ração.

Figure 5 - Regression of the protein intake on the dietary DE level for barrows from 30 to $60 \mathrm{~kg} \mathrm{LW}$ in a high environment temperature.

\section{Conclusões}

Concluiu-se que o nível de $3486 \mathrm{kcal}$ de ED, no qual o óleo contribuiu com 10,53\% da ED total, proporcionou os melhores resultados de ganho de peso, enquanto que o nível de $3700 \mathrm{kcal}$, em que o óleo forneceu 20,85\% da ED total, proporcionou os melhores valores de conversão alimentar de suínos machos castrados de 30 a $60 \mathrm{~kg}$ de peso mantidos em ambiente de alta temperatura $\left(32^{\circ} \mathrm{C}\right)$.

\section{Referências Bibliográficas}

COFFEY, M.T., SEERLEY, R.W., FUNDERBURKE, D.W. et al. 1982. Effect of heat increment and level of dietary energy and environmental temperature on the performance of growing-finishing swine. J. Anim. Sci., 54(1):95-105.

FIALHO, E. T. Influência da temperatura ambiental sobre a utilização da proteína e energia em suínos em crescimento e terminação. In: SIMPÓSIO LATINO-AMERICANO DE NUTRIÇÃO DE SUÍNOS, 1994, São Paulo. Anais... São Paulo: CBNA, 1994. p. 63-83.

FORBES, J.M. 1995. Voluntary food intake and diet selection in farm animals. CAB International. 531p.

OLIVEIRA, R.F.M., DONZELE, J.L., FREITAS, R.T.F., FERREIRA, A.S. 1997. Níveis de energia digestível para leitões dos 15 aos $30 \mathrm{~kg}$ de peso mantidos em ambiente de alta temperatura. R. Bras. Zootec., 26(03):548-556.

ROSTAGNO, H.S., SILVA, D.J. et al. 1992. Composição de alimentos e exigências nutricionais de aves e suínos (Tabelas Brasileiras). Viçosa, MG: UFV, Impr. Univ. 59p.

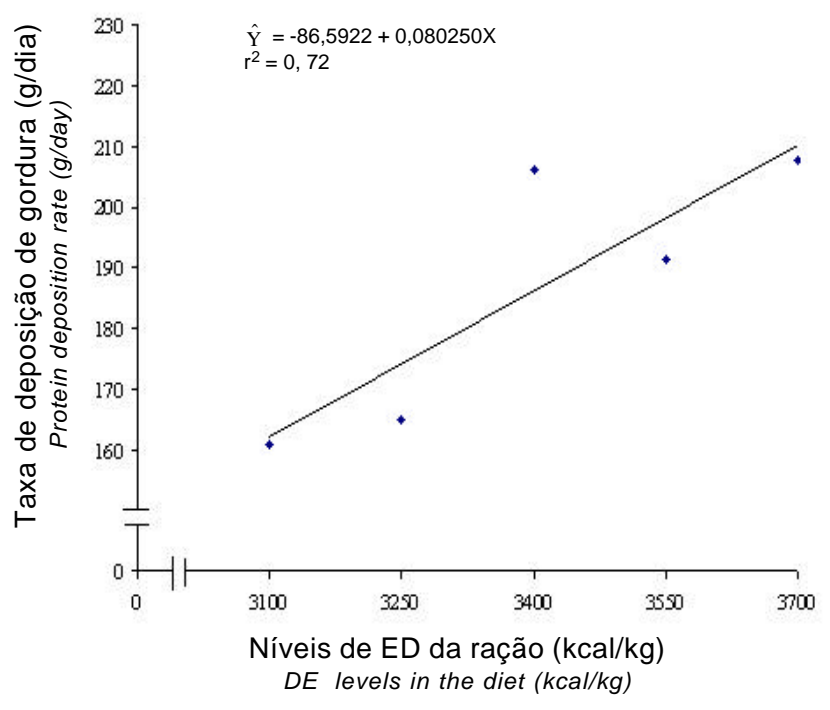

Figura 6 - Regressão da taxa de deposição de gordura de suínos machos castrados dos 30 aos $60 \mathrm{~kg} \mathrm{PV}$ em condições de alta temperatura ambiente em relação ao nível de ED da ração

Figure 6 - Regression of the fat deposition rate on the dietary $D E$ level for barrows from 30 to $60 \mathrm{~kg} \mathrm{LW}$ in a high environment temperature.

SCHENCK, B.C., STAHLY, T.S., CROMWELL, G.L. 1992. Interactive effects of thermal environmental and dietary lisine and fat levels on rate, efficiency, and composition of growth of weanling pigs. J. Anim. Sci., 70:3791-3802.

SCHOENHERR, T.S., STAHLY, T.S., CROMWELL, G.L. 1987. Effects of environmental temperature and dietary fat additions on maintenance and partial efficiency retention in growing swine. J. Anim. Sci., 65:122 (supplement 1).

SEERLEY, R.W., McDANIEL, M.C., McCAMPBELL, H.C. 1992. Environmental influence on utilization of energy in swine diets. J. Anim. Sci., 47(2):3791-3802.

SILVA, D.J. 1990. Análise de alimentos (Métodos químicos e biológicos). Viçosa - MG: UFV, Impr. Univ. 166p.

SPEER, V.C. 1991. Maximizing lean tissue growth: genetic, nutritional, and environmental factors. In: MILLER, E.R., ULLREY, E.D., LEWIS, A.J. (Eds.) Swine nutrition. Butterworth-Heinemann, p.91-102.

STAHLY, T.S., CROMWELL, G.L. 1979. Effect of environmental temperature and dietary fat supplementation on the performance and carcass characteristics of growing and finishing swine. J. Anim. Sci., 49(6):1478-1488.
Recebido em: 29/06/98 Aceito em: 04/12/98 